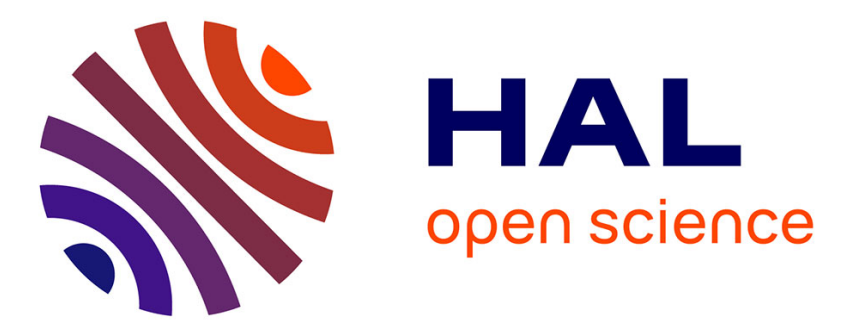

\title{
The generation of the Biot's slow wave at a fluid-porous solid interface. The influence of impedance mismatch
}

\author{
T. Gómez-Alvarez Arenas, E. Riera Franco de Sarabia
}

\section{To cite this version:}

T. Gómez-Alvarez Arenas, E. Riera Franco de Sarabia. The generation of the Biot's slow wave at a fluid-porous solid interface. The influence of impedance mismatch. Journal de Physique IV Proceedings, 1994, 04 (C5), pp.C5-187-C5-190. 10.1051/jp4:1994535 . jpa-00253030

\section{HAL Id: jpa-00253030 https://hal.science/jpa-00253030}

Submitted on 1 Jan 1994

HAL is a multi-disciplinary open access archive for the deposit and dissemination of scientific research documents, whether they are published or not. The documents may come from teaching and research institutions in France or abroad, or from public or private research centers.
L'archive ouverte pluridisciplinaire HAL, est destinée au dépôt et à la diffusion de documents scientifiques de niveau recherche, publiés ou non, émanant des établissements d'enseignement et de recherche français ou étrangers, des laboratoires publics ou privés. 


\title{
The generation of the Biot's slow wave at a fluid-porous solid interface. The influence of impedance mismatch
}

\author{
T.E. GÓMEZ-ALVAREZ ARENAS and E. RIERA FRANCO DE SARABIA \\ UEI Ultrasonidos, Instituto de Acústica, CSIC, Serrano 144, 28006 Madrid, Spain
}

\begin{abstract}
This paper will present a theoretical and an experimental work which deals with the phenomena relating to the interaction of an acoustic wave with an interface between a porous media and a fluid. It is well kown that two different longitudinal waves can propagate through a porous medium, the reflection, transmission and mode conversion in an interface of this kind will be studied in detail. The influence of the impedance of the porous media components on the generation of each mode will be analized and compared with the experimental results.
\end{abstract}

\section{INTRODUCTION.}

Recent published papers [1-3] on the acoustic wave propagation in porous materials have shown not only the observation of two different longitudinal modes, but also the influence of solid and fluid properties on the generation of both modes at the interface between a porous media and a fluid. These modes where predicted by M. A. Biot $[4,5]$ and should appear when an acoustic wave propagates through a porous material. Nevertheless this kind of observation is not easy, and there are only a few works on this subject in which a direct detection of the two longitudinal waves is presented.

In particular, Biot's slow wave has been rarely observed, and the reason for this remains even today unclear. Usually, it is attributed to the high attenuation of this slow wave, but this is not enough to explain why in many experimental cases this wave could not be observed. Some previously published papers [6-8] on the same topic have studied the frecuency spectrum of the reflection and transmission power. The difference in our work lies not only in the treatment of the boundary conditions but also in the final objective.

This paper, presents a theoretical work in which the amount of both modes generated at an interface between a porous media and a fluid is calculated. The influence of the properties of the porous media constituents on the generation of both modes will be analized.

Finally, some experimental results will be presented, in which the influence of fluid properties on the generation of both slow and fast waves is clearly shown.

\section{REFLECTION AND TRANSMISSION PHENOMENA IN A FLUID-POROUS MEDIA INTERFACE. THEORETICAL APPROACH.}

The conventional theories for studying the transmission and reflection phenomena between two elastic and continuum media are not valid when one of the two media is a porous material. In this case, 
there are two different longitudinal modes whereas, in the first case, only one appears. The problem is how to consider the presence of these two different longitudinal modes. As has been already mentioned, there are some theoretical works [6-8] where the problem is solved in terms of the displacement field on each phase of the porous media. In this work, the boundary conditions will be formulated for each phase separately, and expressed in terms of pressures and velocities. The interaction between the two different phases is considered in the relationship between the pressure field for each mode in each phase. This factor is provided by the equations governing the propagation of an acoustic wave in porous media.

Let us imaging now that we have an interface between a fluid and a porous media, and that a plane wave travelling from the fluid to the porous media impinges on this interface at normal incidence.

The pressure field in the fluid $\left(P_{1}\right)$ is:

$P_{1}=A_{i} e^{i(k x-\omega t)}+B e^{-i(k x+\omega t)}$

where $A_{i}$ and $B$ are the amplitude of the incidence and the reflected pressure field respectively.

The pressure field in the porous media $\left(P_{2}\right)$ is:

$P_{2}=A_{R} e^{i\left(k_{\mathrm{R}} x-\omega t\right)}+A_{L} e^{i\left(k_{L} x-\omega t\right)}$

where $A_{R}$ and $A_{L}$ are the amplitude of the fast and slow longitudinal pressure field respectively, and $k_{R}$ and $k_{L}$ are the wave vectors for the two waves, fast and slow.

To solve this problem, the fluid part of the porous media and the solid part will be considered separately. Then we obtain four boundary conditions at $\dot{x}=0$ :

$$
\begin{aligned}
& A_{i}+B^{\prime}=A_{R}^{S}+A_{L}^{S} \\
& \frac{A_{i}-B^{\prime}}{Z_{0}}=\frac{A_{R}^{S}}{Z_{R}^{S}}+\frac{A_{L}^{S}}{Z_{L}^{S}} \\
& A_{i}+B^{\prime \prime}=A_{R}^{F}+A_{L}^{F} \\
& \frac{A_{i}-B^{\prime \prime}}{Z_{0}}=\frac{A_{R}^{F}}{Z_{R}^{F}}+\frac{A_{L}^{F}}{Z_{L}^{F}}
\end{aligned}
$$$$
\text { for the solid }
$$

for the fluid

where $Z$ is the acoustic impedance ( $Z_{0}$ corresponds to the free fluid). The superscripts $S$ and $F$ correspond to solid and fluid, the subindexes $L$ and $R$ to the slow and fast longitudinal modes, and $B^{\prime}$ and $B^{\prime \prime}$ are the amplitude of the pressure fields reflected by the solid and the fluid part of the porous media, respectively.

It is clear now that some additional information is required (we have 4 equations and 6 unknowns).

This information is provided by the equations of motions from which a relationship between the velocity fields for each mode in each phase is obtained. The equations of motion for a longitudinal plane wave in an isotropic porous solid are:

$$
\begin{aligned}
& \nabla^{2}(P e+Q \varepsilon)=\frac{\partial^{2}}{\partial t^{2}}\left(\rho_{11} e+\rho_{12} \varepsilon\right)+b \frac{\partial}{\partial t}(e-\varepsilon) \\
& \nabla^{2}(Q e+P \varepsilon)=\frac{\partial^{2}}{\partial t^{2}}\left(\rho_{12} e+\rho_{22} \varepsilon\right)-b \frac{\partial}{\partial t}(e-\varepsilon)
\end{aligned}
$$

where $e$ and $\varepsilon$ are deformations in the solid and the fluid, respectively, $b$ is the flux resistivity, $\rho_{i j}$ are the density coefficients introduced by Biot, and $P, Q$ and $R$ are the Biot's elastic coefficients of the porous media. obtained:

From these equations, a relationship between velocity fields for each mode in each phase is

$$
\Phi_{L, R}=\left(i \omega b+\rho_{12} \omega^{2}-k_{L, R}^{2} Q\right) /\left(i \omega b-\rho_{22} \omega^{2}+k_{L, R}^{2} R\right)
$$


and now the relationships between the pressure fields are also obtained: $A_{R}^{F}=F_{R} A_{R}^{S}$ and $A_{L}^{F}=F_{L} A_{L}^{S}$ where: $F_{R}=\Phi_{R} Z_{R}^{F} / Z_{R}^{S}$ and $F_{L}=\Phi_{L} Z_{L}^{F} / Z_{L}^{S}$

The equations (4) with these last relations can be analitically solved, obtaining the amplitude of each mode as a function of solid and fluid properties and the couplings between the two different phases.

$$
\begin{aligned}
& A_{L}^{F}=2 A_{i} \frac{1+Z_{0} / Z_{R}^{S}-F_{R}\left(1+Z_{0} / Z_{R}^{F}\right)}{\left(1+Z_{0} / Z_{L}^{F}\right)\left(1+Z_{0} / Z_{R}^{S}\right)-\left(1+Z_{0} / Z_{L}^{S}\right)\left(1+Z_{0} / Z_{R}^{F}\right) F_{R} / F_{L}} \\
& A_{R}^{F}=\left[2 A_{i}-\frac{A_{L}^{F}}{F_{L}}\left(1+\frac{Z_{0}}{Z_{L}^{S}}\right)\right] F_{R} /\left(1+\frac{Z_{0}}{Z_{R}^{S}}\right)
\end{aligned}
$$

\section{EXPERIMENTAL RESULTS.}

Now we will briefly summarize the experimental works which gave rice to the theoretical work presented above. In the first one [1] a novel observation of the two different longitudinal modes in a porous media consisting of three different phases (fabrics, water and air bubbles) were presented. In addition, the effect of the variation of the air content inside the porous media on the observability of the different longitudinal modes was analyzed. It could be observed that as the samples were deaereated (the bulk modulus of the fluid changes: initially it could decrease but after a while it increases steadily up to the value of pure water ) the slow wave disappeared.

In the second work [2], the evolution of the transmitted signals through the same materials as in [1] was studied in detail for the whole range of air bubble concentration inside the porous sample. Figure 1 shows a part of this evolution (the initial stage). Initially (up) there is only transmission in relation to the fast wave $(500 \mathrm{~m} / \mathrm{s})$. Finally (down) there is only transmission in relation to the slow wave $(30 \mathrm{~m} / \mathrm{s})$. The transition between these two stages is associated with an increase in the reflection coefficient from 0.5 to 0.7 , which implies a change in the fast wave velocity from $500 \mathrm{~m} / \mathrm{s}$ to $240 \mathrm{~m} / \mathrm{s}$. The increase in the reflection coefficient is related to an increase in the impedance uncoupling between solid and fluid. It could be established that, for these samples, the uncoupling should be higher than a $67 \%$ in order to generate the slow wave in a sufficiently quantity to be observed.

In the third work [3], similar measurements were performed for the same porous materials but this time in air. In this case, and as a result of the large impedance mismatch between fluid and solid, the fast wave was completely reflected, and only slow wave, travelling at a velocity about $65 \mathrm{~m} / \mathrm{s}$, was detected.

\section{THEORETICAL RESULTS.}

Now the developed theoretical model will be applied to explain the experimental observation discussed above. Therefore this theoretical procedure was applied to a finite thickness porous sample for different values of the bulk modulus of the fluid and for a wide frequency range. Finally, the transmited amplitude of each mode was computed by means of spectral techniques. These results are shown in figure 2 together with experimental measurements from [1] and [2]. A good agreement can be observed.

To explain the experimental measurements shown in the figure 1, first we have to calculate the bulk modulus of the fluid associated to the velocities of $500 \mathrm{~m} / \mathrm{s}$ and $240 \mathrm{~m} / \mathrm{s}$ which determine the transition between the no-transmission of the slow wave to the appearance of it. The result is a change of the bulk modulus of the fluid from $2 \times 10^{8}$ to $2 \times 10^{7}$. The theory predicts a change of the slow wave/fast wave amplitude from 0.002 to 0.8 . This fact explains quite well the evolution of the slow wave shown in figure 1. The fact that the fast wave can not be observed at the botton (figure 1) is due to the attenuation of the air bubbles which is not considered in the model. It should be noted now that the measurements 
presented in [1] and [2] were performed in a frequency range where the attenuation of the air bubbles on the fast wave was almost negligible.

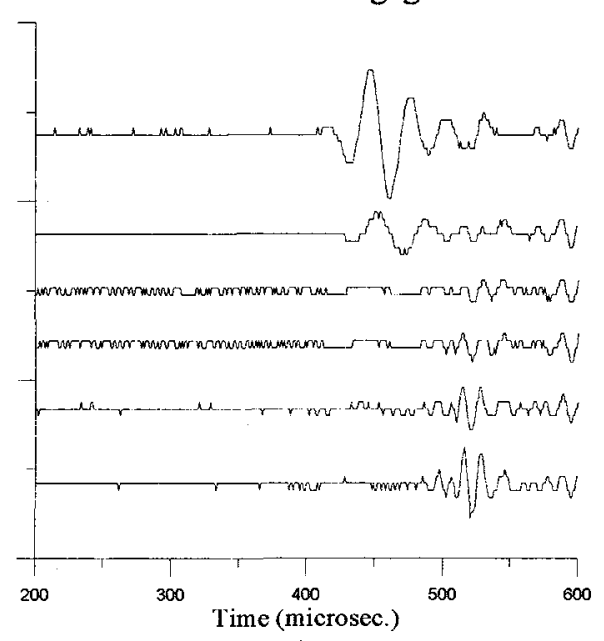

Figure 1

Evolution of the transmitted signals through the porous sample as the deaereation process takes place.

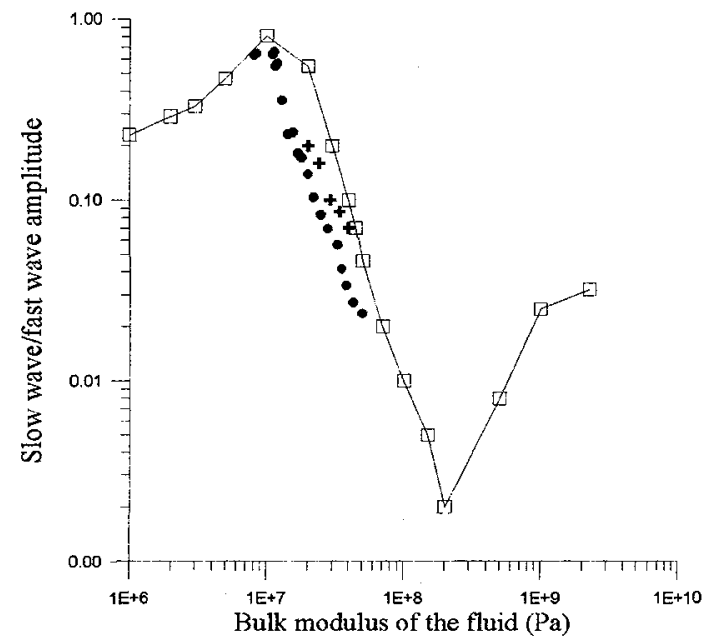

Figure 2

Amplitude ratio of the fast wave to the slow wave versus the bulk modulus of the fluid. $(+),(\bullet),(\square)$ experimental results from [1] and [2], and theoretical predictions, respectively.

\section{CONCLUSIONS.}

A theoretical and an experimental work which studied in detail the influence of fluid properties on the generation of the different Biot's longitudinal modes has been presented. It has been shown that, for the employed samples, the impedance mismatch between solid and fluid must be high in order to detect the slow wave. Since as far as we know, this is the first theoretical and experimental work in which the influence of sample characteristics on the appearance of the Biot's slow wave has been demonstrated. In addition, it can be used not only to study another kind of porous materials and as a tool to predict when can be expected the observation of the Biot's slow wave, but also for explaining the reason because of this wave could not be observed in other type of porous materials.

Acknowledgements: This work has been supported by the proyect CICYT-ROB-91-0723.

\section{References.}

[1] Gómez T.E., Riera E. and Montero F. Ultrasonics (1994) (in press).

[2] Gómez T.E. and Riera E. "Biot's slow wave in porous materials I. Velocity dispersion measurements", Ultrasonics International Vienna 6-9 July 1993 (in press).

[3] Gómez T.E. and Riera E. "Propagación ultrasónica en un medio poroso de tipo fibroso en aire: Detección de la onda lenta de Biot". XXIV Reunión Bienal de la R.S.E.F. Jaca 2-6 Octubre 1993 pp. AC7.

[4] Biot M. J. Acoust. Soc. Am. 28 (1956) 168-178.

[5] Biot M. J. Acoust. Soc. Am. 28 (1956) 179-191.

[6] Ohyoshi T. "Characterization of an inmersed porous layer by ultrasonic waves". 14 th International Congress on Acoustics. Beijing 3-10 September 1992. pp A8-1.

[7] Qiao W. Du G. and Nie S. "Reflection and transmission of elastic wave in layered media inmersed in liquid". 14 th International Congress on Acoustics. Beijing 3-10 September 1992. pp C14-4.

[8] Wang Y. and Jin T. "Sound reflection from porous layers between two solids". 14 th International Congress on Acoustics. Beijing 3-10 September 1992. pp A8-2. 